\title{
¿Uncertainty in Net Surface Heat Flux due to Differences in Commonly Used Albedo Products
}

\author{
ALLISON HOGIKYAN ${ }^{\mathrm{a}}$ \\ Department of Climate and Space Sciences and Engineering, University of Michigan, Ann Arbor, Michigan \\ MEghan F. CRONIN \\ NOAA Pacific Marine Environmental Laboratory, Seattle, Washington \\ DONGXIAO ZHANG \\ Joint Institute for the Study of the Atmosphere and Ocean/University of Washington, Seattle, Washington \\ SEIJI KATO \\ NASA Langley Research Center, Hampton, Virginia
}

(Manuscript received 17 July 2018, in final form 6 September 2019)

\begin{abstract}
The ocean surface albedo is responsible for the distribution of solar (shortwave) radiant energy between the atmosphere and ocean and therefore is a key parameter in Earth's surface energy budget. In situ ocean observations typically do not measure upward reflected solar radiation, which is necessary to compute net solar radiation into the ocean. Instead, the upward component is computed from the measured downward component using an albedo estimate. At two NOAA Ocean Climate Station buoy sites in the North Pacific, the International Satellite Cloud Climatology Project (ISCCP) monthly climatological albedo has been used, while for the NOAA Global Tropical Buoy Array a constant albedo is used. This constant albedo is also used in the Coupled Ocean-Atmosphere Response Experiment (COARE) bulk flux algorithm. This study considers the impacts of using the more recently available NASA Cloud and the Earth's Radiant Energy System (CERES) albedo product for these ocean surface heat flux products. Differences between albedo estimates in global satellite products like these imply uncertainty in the net surface solar radiation heat flux estimates that locally exceed the target uncertainty of $1.0 \mathrm{~W} \mathrm{~m}^{-2}$ for the global mean, set by the Global Climate Observing System (GCOS) of the World Meteorological Organization (WMO). Albedo has large spatiotemporal variability on hourly, monthly, and interannual time scales. Biases in high-resolution $\mathrm{SW}_{\text {net }}$ (the difference between surface downwelling and upwelling shortwave radiation) can arise if the albedo diurnal cycle is unresolved. As a result, for periods when satellite albedo data are not available it is recommended that an hourly climatology be used when computing high-resolution net surface shortwave radiation.
\end{abstract}

D Denotes content that is immediately available upon publication as open access.

\footnotetext{
${ }^{a}$ Current affiliation: Atmospheric and Oceanic Sciences Program, Princeton University, Princeton, New Jersey.
}

Corresponding author: Meghan F. Cronin, meghan.f.cronin@ noaa.gov

\section{Introduction}

Energy from the sun provides nearly all of the energy entering the Earth system, driving circulation in both the atmosphere and ocean (Trenberth et al. 2009). Because the heat capacity of water is large, the oceanic surface layer can be heated in one location (e.g., the tropics) and then transported to another region (e.g., extratropics) where the heat can be released to the atmosphere, 
affecting atmospheric phenomena including storm development and storm tracks (Minobe et al. 2008; Booth et al. 2017; Trenberth and Fasullo 2010). Understanding surface energy balance, in particular the net solar radiation entering the ocean and its spatial distribution, is thus critical for understanding how the oceans can influence weather and climate, and the long-term distribution of heat between the oceans and atmosphere.

As solar radiation transmits through the atmosphere, nearly $30 \%$ of the energy is reflected back to space by clouds and Earth's surface, about $22 \%$ of the energy is absorbed by the atmosphere, and the rest is absorbed by the surface (e.g., L'Ecuyer et al. 2015; Stephens et al. 2012; Kiehl and Trenberth 1997). The total solar radiation that impinges on the ocean's surface (i.e., insolation) is thus reduced from the insolation at the top of the atmosphere, is highly variable in space and time, and can be either partially or wholly diffuse (e.g., Hatzianastassiou et al. 2005). The fraction that is reflected off the ocean surface depends on the characteristics of both the insolation and the ocean surface (Jin et al. 2004; Feng et al. 2016) and is referred to as the ocean surface albedo $\alpha$. Despite its important role in the ocean surface energy budget, $\alpha$ has often been highly simplified in numerical models (e.g., Wild et al. 2013, and references therein) and parameterizations (e.g., Fairall et al. 1996, 2003).

Shortwave $\alpha$ is defined as the ratio of upward (i.e., reflected; $\mathrm{SW}_{\mathrm{up}}$ ) to downward (downwelling, or incoming; $\left.\mathrm{SW}_{\text {down }}\right)$ shortwave radiation:

$$
\alpha=\frac{\mathrm{SW}_{\text {up }}}{\mathrm{SW}_{\text {down }}} .
$$

The time resolution of albedo matches the time resolution of $\mathrm{SW}_{\text {down }}$ and $\mathrm{SW}_{\text {up }}$ for our calculations. For example, hourly or monthly averaged $\mathrm{SW}_{\text {down }}$ and $\mathrm{SW}_{\text {up }}$ are used to estimate, respectively, the hourly or monthly averaged albedo. Likewise, an hourly or monthly averaged $\mathrm{SW}_{\text {down }}$ and albedo can be used to estimate the corresponding hourly or monthly averaged $\mathrm{SW}_{\text {up }}$ and thus the net surface shortwave radiation. In this study, we investigate the temporal and spatial variability of $\alpha$, as well as the difference in the monthly climatology associated with two satellite products and from a parameterization commonly used in oceanographic studies. Then, we quantify the uncertainty in the surface heat budget resulting from these differences.

While $\mathrm{SW}_{\text {down }}$ can be measured from radiometers mounted on towers, ships, and buoys, $\mathrm{SW}_{\text {up }}$ is quite difficult to measure (Payne 1972). Payne (1972), Jin et al. (2004), and others have done so but it is more common that the net shortwave radiation $\left(\mathrm{SW}_{\text {net }}\right)$, the difference between the downward and upward components, is estimated using in situ $\mathrm{SW}_{\text {down }}$ and remotely sensed, parameterized albedo (e.g., Yu and Weller 2007; Cronin et al. 2015; Payne 1972; Taylor et al. 1996; Jin et al. 2004) or a constant value of 0.055 , based upon historical measurements from Payne (1972). For example, the Payne (1972) value is used for net shortwave radiation provided at NOAA Global Tropical Moored Buoy Array (GTMBA) sites (www.pmel.noaa.gov/tao/drupal/flux/; Cronin et al. 2006), as well as at the Southern Ocean flux site (Schulz et al. 2012). This value is also hardwired into the warm-layer correction model of the Fairall et al. (1996, 2003) Coupled Ocean-Atmosphere Response Experiment (COARE) bulk flux algorithm and will be referred to as $\alpha_{\mathrm{COARE}}$. In contrast, the NOAA Ocean Climate Stations (OCS) group has historically used a satellite-derived monthly climatological albedo provided by the International Satellite Cloud Climatology Project (ISCCP) (Zhang et al. 2004) in combination with in situ $\mathrm{SW}_{\text {down }}$ to calculate net shortwave radiation, $\mathrm{SW}_{\text {net }}$, which is provided for public download from their website (www.pmel.noaa.gov/ocs/ data/fluxdisdel; Zhang et al. 2016). OCS manages buoy sites Papa and KEO (the Kuroshio Extension Observatory) in the North Pacific. Data from these sites are described in detail in section 2a. This study was motivated by a need to understand the impacts of switching from using ISCCP monthly albedo climatology for their $\mathrm{SW}_{\text {net }}$ product to the high-temporal-resolution CERES albedo product. The ISCCP monthly climatological albedo has been used even for hourly and daily $\mathrm{SW}_{\text {net }}$ time series at the OCS buoy sites for both near-real time and delayed mode. As we will show and quantify, this mismatch in time scales between the climatological monthly albedo and hourly $\mathrm{SW}_{\text {down }}$ introduces uncertainty into the local $\mathrm{SW}_{\text {net }}$ greater than the target uncertainty for global mean surface heat fluxes of $1 \mathrm{~W} \mathrm{~m}^{-2}$ set by the World Meteorological Organization's (WMO) Global Climate Observing System (GCOS; GCOS 2018). This target uncertainty in global mean surface heat flux represents the accuracy needed to resolve anthropogenic global warming (Pierce et al. 2006). Although the value was developed as a target for global average flux observations, we use it throughout this study as a useful target for local flux observations.

We also show that the choice of albedo products can introduce uncertainties greater than the GCOS target uncertainty. In particular, we compare the constant albedo value used in the COARE algorithm to the monthly climatologies of the widely used ISCCP albedo product and the newer albedo product from the NASA Cloud and the Earth's Radiant Energy System (CERES) project (Wielicki et al. 1996). The CERES-derived 


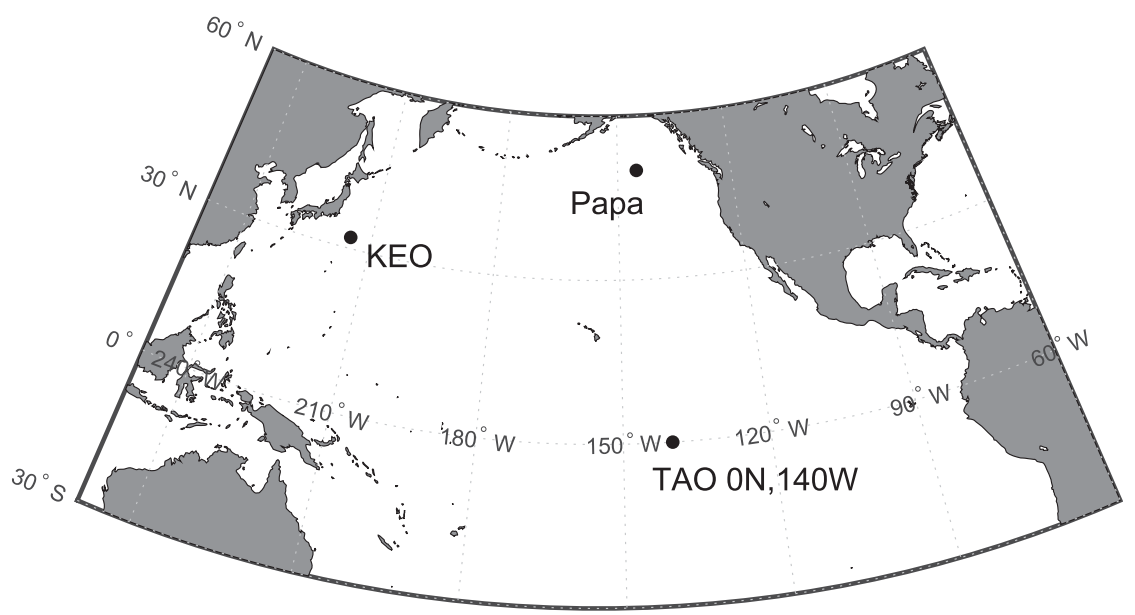

FIG. 1. Buoy locations used in this study.

surface albedo model is based on Jin et al. (2004), which is a function of solar zenith angle (SZA), cloud fraction, aerosol loading, and wind speed, as well as surface color, largely dictated by chlorophyll concentration. While Jin et al. (2004) suggest that sediments, plankton, and bubbles in the surface layer of ocean are likely the largest source of error in the model, these errors should be small in the open ocean. We thus use this newer albedo product, which has the advantage of up-to-date and continuing data, to explore the diurnal and interannual variability at three open-ocean buoy locations in the North Pacific. The three buoy locations represent a range of different regimes, from the equator to subtropical and subpolar gyres (Fig. 1). In general, shortwave radiation at a point location becomes more representative of a spatial footprint with increasing time averaging. For example, Kato et al. (2018) show that when averaged over monthly time scales, the mean bias in downward shortwave radiation from a buoy and $1^{\circ} \times 1^{\circ}$ grid reduces to $5 \mathrm{~W} \mathrm{~m}^{-2}$ (see their Fig. 11). Because ocean albedo tends to be more spatially uniform than shortwave radiation, it is expected that a $1^{\circ}$ footprint in ocean albedo could represent a point value, even at subdiurnal time scales. We begin by describing the buoy and satellite data used in this study, then compare the COARE, ISCCP, and CERES albedos, and finally quantify the heat budget uncertainty due to albedo uncertainty at various time scales.

\section{Data and methods}

\section{a. Buoy data}

Downwelling shortwave radiation observations from three open-ocean moored buoys will be used in this study and referred to as $\mathrm{SW}_{\text {down,buoy; }}$ upwelling shortwave radiation estimated from an albedo and $\mathrm{SW}_{\text {down,buoy }}$ will be referred to as $\mathrm{SW}_{\text {up,buoy. Unless }}$ otherwise noted, these shortwave radiation estimates are used to calculate surface heat budget sensitivity to albedo since we expect $\mathrm{SW}_{\text {down,buoy }}$ to be more accurate than either $\mathrm{SW}_{\text {down,CERES }}$ or $\mathrm{SW}_{\text {down,ISCCP. The source }}$ used for $\mathrm{SW}_{\text {down }}$ is labeled in each figure caption. Buoys analyzed here include the Kuroshio Extension Observatory (KEO) at $32.3^{\circ} \mathrm{N}, 144.5^{\circ} \mathrm{E}$ in the northwest Pacific subtropical recirculation gyre, Station Papa at $50.1^{\circ} \mathrm{N}$, $144.9^{\circ} \mathrm{W}$ in the northeast Pacific subpolar gyre, and a site at the equator $\left(0^{\circ}, 160^{\circ} \mathrm{W}\right)$ from the Tropical Atmosphere Ocean (TAO) array, a component of the GTMBA. KEO and Papa are maintained by the NOAA Ocean Climate Stations group (Cronin et al. 2015). The buoymeasured $\mathrm{SW}_{\text {down }}$ at KEO and Papa are downloaded from the OCS Mooring Data web page, https:// www.pmel.noaa.gov/ocs/data/disdel/. The NOAA National Data Buoy Center (NDBC) maintains TAO data. Downwelling shortwave radiation for the TAO sites can be accessed at http://tao.ndbc.noaa.gov/tao/ data_download/search_map.shtml. For all buoys, shortwave radiation is measured with an Eppley pyranometer at $1 \mathrm{~Hz}$ and output as either 1- or 2-min averages, from which hourly averages are computed. Colbo and Weller (2009) report pyranometer accuracy of $\pm 1 \%$ and a mean bias of $5 \mathrm{~W} \mathrm{~m}^{-2}$ in irradiance measured by a pyranometer on buoy (also at https:// www.pmel.noaa.gov/ocs/sensors). For TAO buoys, high-resolution data (2-min) are telemetered in near-real time, while hourly averages are telemetered for OCS buoys. Delayed-mode, postprocessed high-resolution data at all sites are generally available several months after the buoy has been recovered from its roughly 1-yr deployment. Data gaps due to sensor or mooring failure are not filled. 


\section{b. ISCCP data}

The ISCCP-FH Radiative Flux Profile Product is the third-generation high-resolution flux product and primarily uses ISCCP H-series cloud products (Y. Zhang 2019, personal communication): it includes upwelling and downwelling shortwave radiative fluxes at the surface on a $110-\mathrm{km}$ equal-area global grid available from July 1983 to June 2009. We calculate albedo from the fluxes, since albedo is not directly provided, according to (1). For this study, we use only monthly ISCCP albedo $\alpha_{\mathrm{ISCCP}}^{\text {month }}$ based on the monthly average subproduct downloaded from the ISCCP ftp site (https://isccp.giss.nasa.gov/pub/flux-fh/tar-nc4_MPF/). Note that the shortwave range is $0.2-5 \mu \mathrm{m}$. The ISCCP calculation of upwelling fluxes over ocean relies on the GISS radiation model. Zhang et al. (2004) describe the upwelling radiation in the GISS model as a product of modeled downwelling shortwave radiation and surface albedo, which is a function of solar zenith angle and other optical properties of the ocean.

Since all buoy sites considered are open ocean and at least two satellite grid cells from land, we expect there to be no averaging errors in satellite albedo due to land.

\section{c. CERES data}

The CERES project provides averaged surface fluxes (Wielicki et al. 1996) at 3-hourly and monthly time scales from which we compute surface albedo $\alpha_{\text {CERES }}$ according to (1). The CERES broadband scanning radiometers are considered an improvement from those used by Earth Radiation Budget Experiment (ERBE; Barkstrom 1984) with 2-3 times less error. Specific improvements to the radiometers are listed in Wielicki et al. (1996). We use data during the period from 1 January 2001 to 31 December 2016, the longest series of full years available from CERES at the time of analysis. The $1^{\circ}$-resolution monthly Synoptic Radiative Fluxes and Clouds (SYN1deg-month, edition 3A) upwelling and downwelling surface all-sky shortwave radiation data, including all wavelengths of reflected radiation (Loeb et al. 2001), were downloaded and used to calculate monthly albedo. To compute an hourly albedo to match the buoy data, we use 3-hourly average (Rutan et al. 2015) $\mathrm{SW}_{\text {down }}$ and $\mathrm{SW}_{\text {up }}$ time series (SYN1deg-3H), linearly interpolated to hourly values. $\mathrm{SW}_{\text {down }}$ values of zero, which occur overnight, are removed to avoid error due to division by zero in (1).

The CERES flux product is updated at least once per year and thus can usually provide a timely surface albedo value for delayed-mode data at the buoy sites. Monthly and hourly albedo climatology calculations appropriate for calculating monthly and hourly $\mathrm{SW}_{\mathrm{up}}$ are documented in section 2e. Monthly and 3-hourly time series were accessed from http://ceres.larc.nasa.gov/ order_data.php.

In situ measurements are available for comparison to monthly CERES data in the CERES download tool (https://ceres-tool.larc.nasa.gov/cave/jsp/CAVESelection. jsp) from the CERES/ARM Validation Experiment (CAVE) (Rutan et al. 2001). The averages of monthly errors from $\mathrm{SW}_{\text {down,CERES }}$ relative to mooring observations, for June $2004-J u n e ~ 2015$, are $-1.9 \mathrm{Wm}^{-2}$ $(-0.3 \%)$ at $\mathrm{KEO},-0.14 \mathrm{~W} \mathrm{~m}^{-2}(-0.3 \%)$ at Papa, and $+0.35 \mathrm{~W} \mathrm{~m}^{-2}(2.3 \%)$ at the TAO $\left(0^{\circ}, 160^{\circ} \mathrm{W}\right)$ site. Again, since all buoy sites considered are open ocean and at least two satellite grid cells from land, we expect there to be no averaging errors in satellite albedo due to land.

\section{d. Error and uncertainty terminology}

While at this stage we make no claim that the CERES product is more accurate than the ISCCP product, as discussed in the previous sections, the physics of the albedo model used by CERES is more sophisticated than that used by ISCCP. Finally, while the CERES product does not extend as far back in time, it will continue to extend into the future, and so will be contemporary with buoy data going into the future. For these reasons there is an interest in transitioning to the CERES albedo product to calculate $\mathrm{SW}_{\text {net }}$ at buoy sites. Since we know that both satellite estimates are imperfect, we will maintain the term difference or uncertainty rather than error to describe differences between satellite estimates of surface heating. Since we know that the diurnal cycle in albedo and $\mathrm{SW}_{\text {net }}$ is real, errors associated with neglecting the diurnal cycle will be referred to as such. The guideline we use to define "large" error is produced by GCOS and defines target error in surface heat fluxes to be $1 \mathrm{~W} \mathrm{~m}^{-2}$ for a global mean. GCOS is a program of the United Nations to assess and set goals for improving observations of the global climate.

\section{e. Climatological surface albedo}

Since the satellite-based albedo time series are not as up to date as buoy telemetry, climatological albedo must be used for recent and near-real-time estimates of $\mathrm{SW}_{\text {net }}$. To compare ISCCP and CERES products, a monthly climatology is computed for the common overlap period of January 2001-December 2009. For CERES, 3-hourly time series are available and are used to create climatologies of hourly $\alpha$. In particular, shortwave albedo $\alpha_{\text {CERES }}^{\text {hour }}$ is computed from the full 15 years of 3-hourly CERES upward and downward shortwave radiation according to (1) and linearly interpolated to hourly values. 
The hourly albedos are then binned into months to create one climatological diurnal cycle per month (12 distinct 24-h days). Thus, $\alpha_{\text {CERES }}^{\text {Clim,hour }}$ then consists of 31 repeats of $\left\langle\alpha_{\text {CERES }}^{\text {hour,January }}\right\rangle$, followed by 28 or 29 repeats of $\left\langle\alpha_{\text {CERES }}^{\text {hour,Febrary }}\right\rangle$, etc., where angle brackets here denote an average over each hour of the day.

\section{f. Calculation of heat budget sensitivity to albedo}

Throughout our analysis, we consider the impact of spatial and temporal variability, and the difference between products, on the surface heat budget by calculating an uncertainty in $\mathrm{SW}_{\text {net }}$ from an uncertainty in albedo $\Delta \alpha$

$$
\Delta \mathrm{SW}_{\text {net }}=-\mathrm{SW}_{\text {down,buoy }} \Delta \alpha,
$$

since $\mathrm{SW}_{\text {net }}=\mathrm{SW}_{\text {down }}-\mathrm{SW}_{\text {up }}=\mathrm{SW}_{\text {down }}(1-\alpha)$. We do not provide an analysis of the uncertainty in $\mathrm{SW}_{\text {down }}$ because it is documented in other studiesfor example, Wielicki et al. (1996) for CERES and MacWhorter and Weller (1991) for in situ buoy and ship observations. In the analysis of the albedo diurnal cycle, we wish to understand the impact of calculating skin temperature based upon the surface radiative and turbulent heat fluxes and bulk SST using the constant COARE albedo, as is done in the Fairall et al. (1996) warm-layer correction. For this case, $\Delta \alpha$ is the difference between the CERES hourly albedo and the constant albedo value used in the Fairall et al. (1996) warm-layer correction. In contrast, in the analysis of the interannual variability, $\Delta \alpha$ is the difference between $\alpha_{\text {CERES }}^{\text {month }}$ and $\alpha_{\text {CERES }}^{\text {Clim,month }}$, and in the comparison of the two products, $\Delta \alpha$ is the difference between $\alpha_{\text {CERES }}^{\text {Clim,month }}$ and $\alpha_{\text {ISCCP }}^{\text {Clim,month }}$. In the calculation of $\mathrm{SW}_{\text {net }}$, the albedo resolution must always match the $\mathrm{SW}_{\text {down }}$ resolution. If $\mathrm{SW}_{\text {down }}$ resolves the diurnal cycle but albedo does not, $\mathrm{SW}_{\text {net }}$ will be biased, as discussed in section $3 c(3)$. Resolutions are labeled throughout.

The impact of $\Delta \alpha$ on the vertically averaged temperature within the mixed layer $T_{\mathrm{ML}}$, by way of its impact on $\mathrm{SW}_{\text {net }}$, can be evaluated by considering the mixed-layer temperature budget as in Cronin et al. (2013):

$$
\frac{\delta T_{\mathrm{ML}}}{\delta t}=\mathrm{SW}_{\text {net }}\left(\rho c_{p} H\right)^{-1},
$$

where $\rho$ is water density, $c_{p}$ is specific heat of water, $t$ is time, and $H$ is the mixed layer depth (MLD), above which temperature has little or no stratification and its vertical average $T_{\mathrm{ML}}$ is nearly identical to the sea surface temperature. Using the chain rule to propagate errors, $\Delta T$ depends on $\Delta \mathrm{SW}_{\text {net }}$ according to

$$
\Delta T_{\mathrm{ML}} \text { due to } \Delta \mathrm{SW}_{\mathrm{net}}=\frac{\Delta \mathrm{SW}_{\text {net }}}{\rho c_{p} H} \Delta t .
$$

For the analysis of error associated with the resolution of the diurnal cycle of albedo compared to $\alpha_{\mathrm{COARE}}$, we consider the effects upon the vertically averaged temperature within a shallow $H=2$-m warm layer, denoted by $\Delta T_{2 \mathrm{~m}}$, and integrate the error over $24 \mathrm{~h}$, to produce $\Delta T_{2 \mathrm{~m}}$. Nighttime is implicitly ignored because $\mathrm{SW}_{\text {net }}$ is zero when there is no insolation. A more sophisticated analysis is possible, but to determine the scale of the differences, this simple analysis is sufficient. For analysis of differences between the climatologies we consider $H$ the depth at which the temperature is $0.2^{\circ} \mathrm{C}$ less than the temperature at 10-m depth (de Boyer Montégut et al. 2004). Using the subsurface temperature measurements by the three buoys, we estimated a summer (winter) mixed layer depth $H$ of $33 \mathrm{~m}(119 \mathrm{~m})$ at KEO in the subtropical recirculation gyre, (Cronin et al. 2013), $43 \mathrm{~m}$ $(65 \mathrm{~m})$ at Papa in the subpolar gyre (Cronin et al. 2015), and $23 \mathrm{~m}(28 \mathrm{~m})$ at TAO (not shown).

\section{Results}

\section{a. CERES-ISCCP differences}

In Fig. $2 \mathrm{~b}$ the CERES-calculated $60^{\circ} \mathrm{S}-60^{\circ} \mathrm{N}$ mean ocean $\alpha$ is 0.076 . The magnitude of the difference between the average ISCCP and CERES albedos varies from $5 \%$ to $30 \%$ of the CERES ocean $\alpha$ (Fig. 2 d). As we show in section $3 \mathrm{~b}$, these differences are larger than the natural interannual variability of the albedo. Because albedo is not well defined during polar night and spurious values are present even in summer, areas north and south of $60^{\circ}$ latitude are excluded from our analysis. The bias between sources depends on latitude (Figs. 2b,d and 3), which suggests that albedo dependence on SZA differs between the CERES and ISCCP albedo models. The difference also varies horizontally, as a result of the different satellite cloud retrievals and model dependence on cloud cover.

\section{b. Albedo temporal characteristics and uncertainty at buoys}

\section{1) Seasonal cycle AND interannual VARIABILITY}

Figure 3 shows that the seasonal cycle in albedo increases with increasing latitude, while the typical diurnal cycle amplitude decreases with increasing latitude. At TAO, the monthly climatologies are all quite similar, with mean values of 0.058 for both ISCCP and 0.049 for CERES, with COARE in the middle at 0.055 , which 

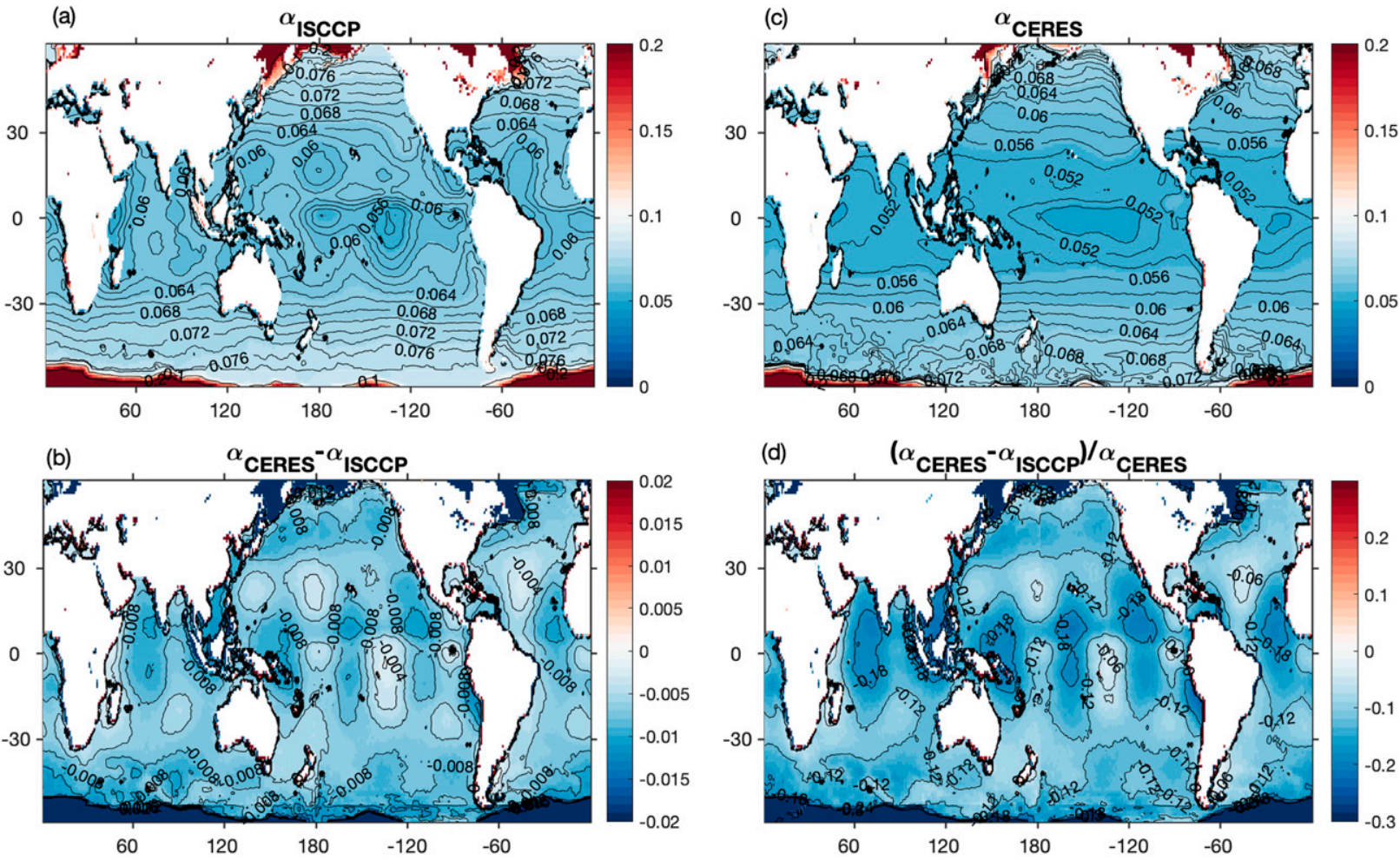

FIG. 2. Mean ocean surface albedo over $60^{\circ} \mathrm{S}-60^{\circ} \mathrm{N}$ from (a) ISCCP and (c) CERES. (b) The mean difference between CERES and ISCCP $\left(\alpha_{\text {CERES }}-\alpha_{\text {ISCCP }}\right)$ and (d) the relative difference between the two products $\left(\alpha_{\text {CERES }}-\alpha_{\text {ISCCP }}\right) / \alpha_{\text {CERES }}$. Contour intervals are 0.002 for (a)-(c) and 0.03 for (d).

makes sense since COARE is based on observations in the tropics. The seasonal cycle at TAO has two distinct peaks of equal magnitude (visible in Fig. 4), associated with the two times that the sun crosses the equator each year, in the transition to Northern Hemisphere summer, and then to Southern Hemisphere summer, which highlights the primary importance of SZA to albedo. CERES monthly albedo displays a larger amplitude annual cycle than ISCCP at Papa and KEO (Figs. 3 and 4). At the equatorial site TAO, ISCCP and CERES observations seem to capture a similar magnitude annual cycle.

The magnitude of the interannual variability in the CERES albedo increases in amplitude with latitude of the sites (Fig. 4). Interannual variability is large relative to the amplitude of the seasonal cycle at TAO in ISCCP, while for CERES, the seasonal cycle is the dominates at Papa, KEO, and TAO. As shown in Table 1, the rootmean-square difference (RMSD) associated with interannual variability is greater at Papa than the other two sites. RMSD associated with interannual variability is smaller in ISCCP than in CERES at each site (not shown). RMSD from $\alpha_{\text {CERES }}^{\text {month }}-\alpha_{\text {COARE }}$ is comparable to that from $\alpha_{\text {CERES }}^{\text {month }}-\alpha_{\text {CERES }}^{\text {Clim,month }}$. RMSD between sources (i.e., $\alpha_{\text {CERES }}^{\text {Clim,month }}-\alpha_{\text {ISCCP }}^{\text {Climth }}$ ) is fairly large, $14 \%-18 \%$ of average CERES values (Table 1), showing that the source of albedo contributes a larger error to $\mathrm{SW}_{\text {net }}$ than the $1 \%$ random error from $\mathrm{SW}_{\mathrm{down}}$ buoy sensors.

\section{2) DIURNAL CYCLE}

The diurnal cycle of albedo covaries with SZA (i.e., the hour of day) so that highest albedo occurs when the sun is low in the sky (morning and evening) and lowest albedo (most absorption) occurs when the sun is directly overhead (midday). In Fig. 3, the diurnal cycle amplitude in each month is visualized for comparison to the seasonal cycle amplitude. As described in section 2e, there is one climatological day for each month, so the vertical lines in this figure represent the climatological day for each month. Due to the strong dependence of albedo on SZA, the diurnal cycle is comparable to the seasonal cycle in the subpolar regions (Fig. 3a) and subtropics (Fig. 3b) and overwhelms the seasonal cycle in the tropics (Fig. 3c). The amplitude of the climatological diurnal cycle is about $0.06(0.04)$ in January (August) at Papa, 0.01 (0.13) in January (August) at $\mathrm{KEO}$, and 0.08 (0.1) in January (August) at TAO, while the seasonal cycle amplitude is about 0.025 at Papa, 0.01 at KEO, and 0.005 at TAO (Fig. 3). The monthly means of hourly albedo are higher than monthly albedo at all 


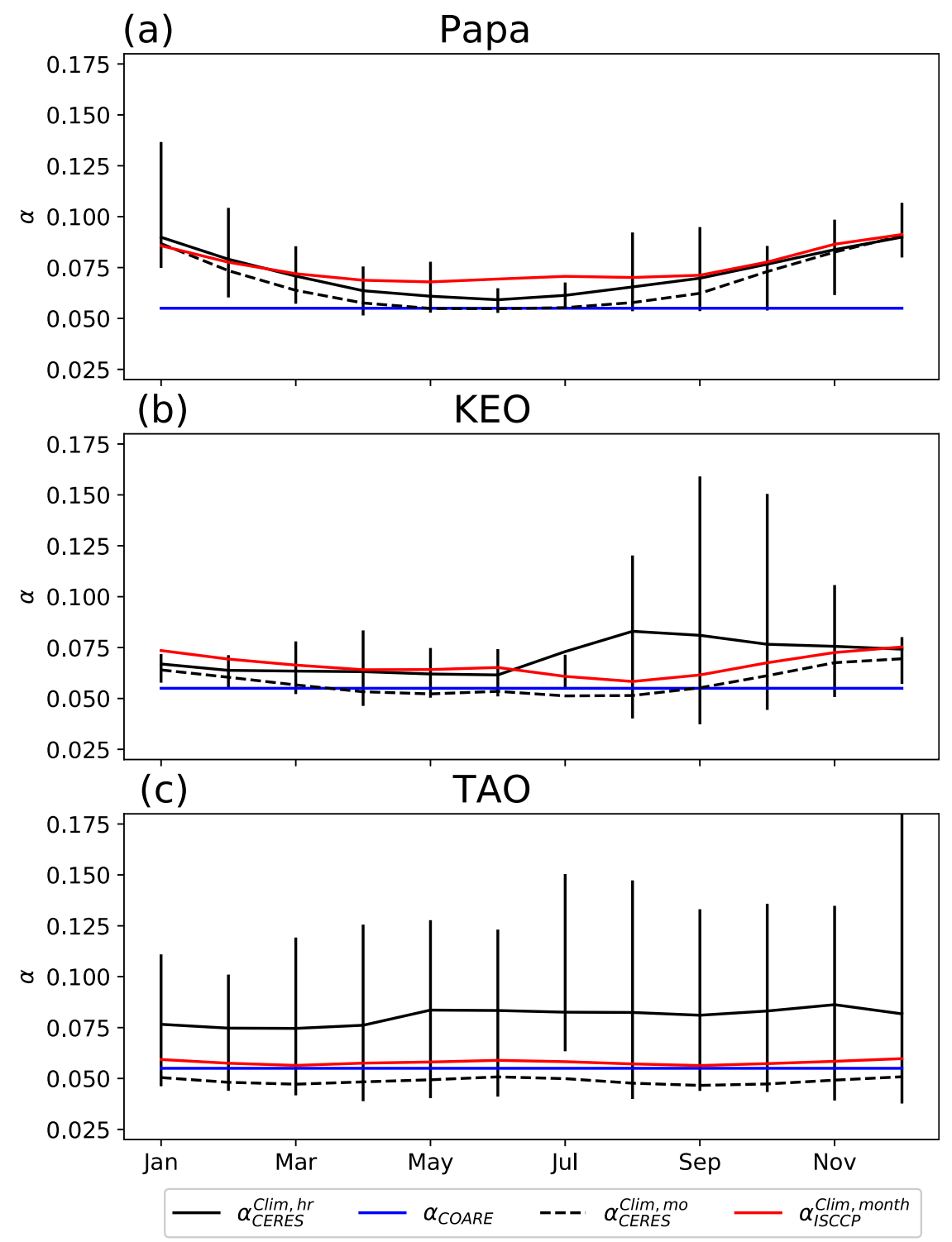

FIG. 3. Climatological monthly and hourly albedo and COARE albedo at (a) Papa, (b) KEO, and (c) TAO. Albedo monthly climatologies for $\alpha_{\text {CERES }}^{\text {Clim,month }}$ are shown as black dashed lines and for $\alpha_{\text {ISCCP }}^{\text {Clim,month }}$ as red lines. Since the climatological diurnal cycles $\alpha_{\text {CERES }}^{\text {Clim,hour have a shorter time }}$ scale than the $x$ axis, the climatological diurnal cycle amplitude in each month is visualized as a black vertical line. The mean hourly albedo values for each month are connected with a solid black line. The COARE surface albedo $\alpha_{\mathrm{COARE}}$ of 0.055 is shown in blue.

three sites because large SZA in morning and late afternoon creates very high $\mathrm{SW}_{\text {up }}$ and low $\mathrm{SW}_{\text {down }}$. In contrast, on monthly time scales, SZA depends primarily upon latitude and season (not on time of day), and is thus relatively small in the tropics and large during winter at higher latitudes. However, SZA is large all day long in winter at high latitudes regardless of temporal resolution. Thus, hourly albedo has the largest differences from monthly climatologies in the tropics. We will quantify the uncertainty in surface heating due to interannual variability and the diurnal cycle in section $3 \mathrm{c}$ and compare each to the GCOS target uncertainty of $1 \mathrm{~W} \mathrm{~m}^{-2}$ for the global mean net solar radiation heat flux.

\section{c. Importance of albedo variability and uncertainty on heat budget and SST estimations}

\section{1) Annual heat Budget}

Now we investigate how important these and other differences in the albedo products are to ocean surface 
(a)

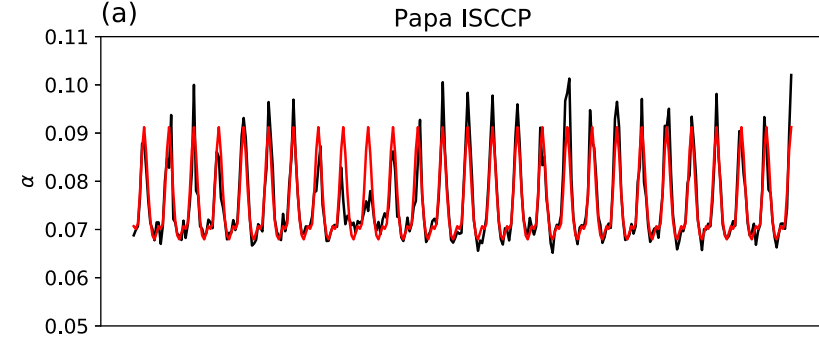

(b)
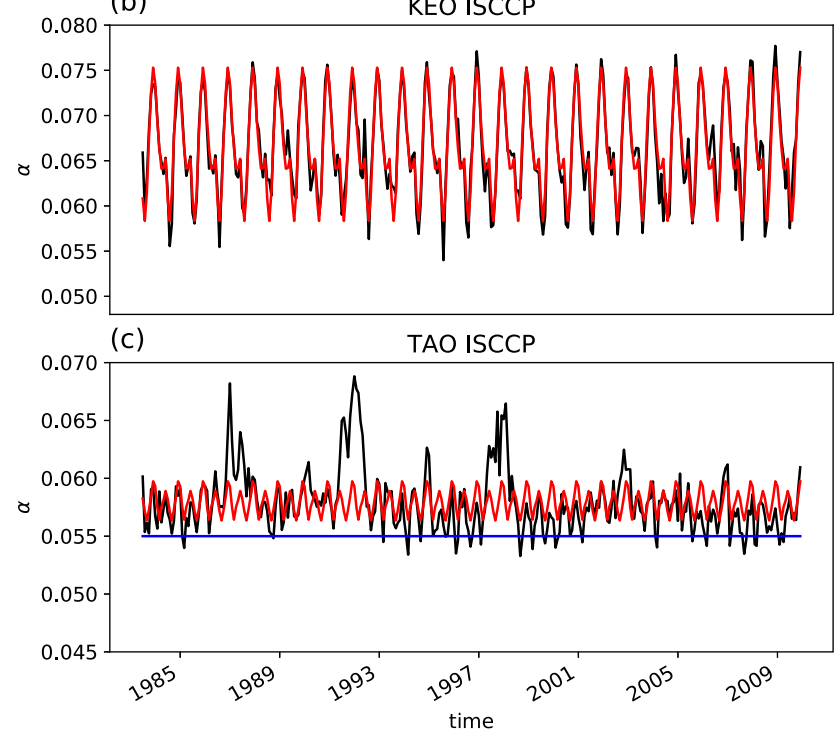

(d)

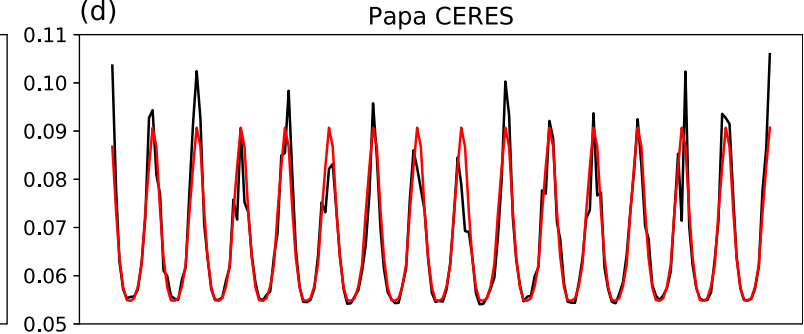

(e)

KEO CERES

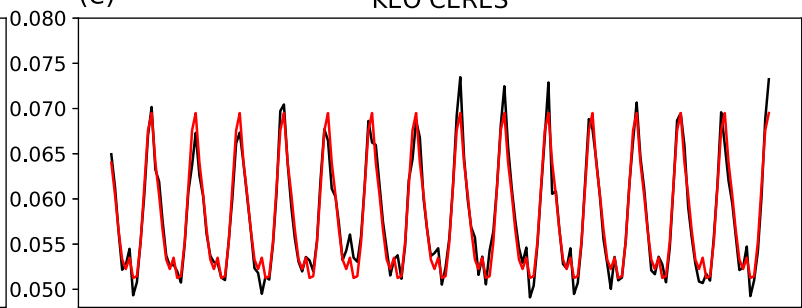

(f) TAO CERES

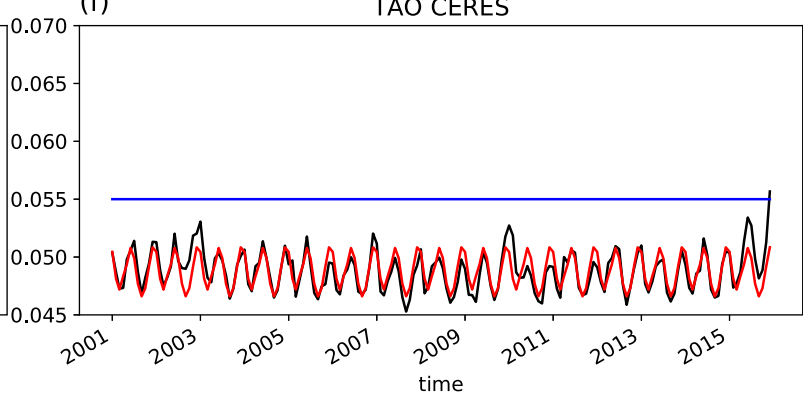

FIG. 4. ISCCP and CERES albedo vs climatology at buoy locations. Climatology is in red and monthly albedo is in black at each buoy location: (a)-(c) $\alpha_{\text {ISCCP }}^{\text {Clim,month }}$ and $\alpha_{\text {ISCCP }}^{\text {month }}$ and (d)-(f) $\alpha_{\text {CERES }}^{\text {Clim,month }}$ and $\alpha_{\text {CERES }}^{\text {month }}$, at (top) Papa, (middle) KEO, and (bottom) TAO. The COARE surface albedo $\alpha_{\mathrm{COARE}}$ is also plotted (blue line) for TAO since the constant value has been historically used in place of climatology for all TAO buoys. Note that the $x$-axis ranges are different for the two datasets, and the $y$-axis ranges are different for the different sites.

heating estimates [Eq. (2)] and surface temperature [Eq. (4)]. As can be seen in Fig. 5, the bias (mean error) in the $\mathrm{SW}_{\text {net }}$ due to the difference in albedo sources is consistently larger (not shown) than bias from neglecting interannual variability and is often larger than
GCOS target uncertainty. The 6-month-mean bias is greater than target uncertainty in summer at Papa and $\mathrm{KEO}$, and in the winter at Papa as well (Table 2b). Because observed $\mathrm{SW}_{\text {down,buoy }}$ is used to compute $\Delta \mathrm{SW}_{\text {net }}$ for Fig. 5 , their differences are due to albedo

TABLE 1. RMSD associated with Fig. 4 comparisons of CERES monthly albedo relative to its monthly climatology $\left(\alpha_{\text {CERES }}^{\text {month }}-\alpha_{\text {CERES }}^{\text {Clim,month }}\right)$, the ISCCP monthly climatology $\left(\alpha_{\text {CERES }}^{\text {Clim,month }}-\alpha_{\text {ISCCP }}^{\text {Clim,month }}\right)$, the COARE value $\left(\alpha_{\text {CERES }}^{\text {month }}-\alpha_{\text {COARE }}\right)$, and the impacts on net heating at the buoy sites: $-\mathrm{SW}_{\text {down,buoy }}^{\text {month }}\left(\alpha_{\text {CERES }}^{\text {month }}-\alpha_{\text {CERES }}^{\text {Clim,month }}\right),-\mathrm{SW}_{\text {down,buoy }}^{\text {month }}\left(\alpha_{\text {CERES }}^{\text {Clim,month }}-\alpha_{\text {ISCCP }}^{\text {Clim,month }}\right),-\alpha_{\text {down,buoy }}\left(\alpha_{\text {CERES }}^{\text {month }}-\alpha_{\text {COARE }}\right)$. CERES monthly climatology was calculated over the full available time period. The percentages in parentheses indicate the proportion relative to $\alpha_{\text {CERES }}^{\text {month }}$.

\begin{tabular}{lcc}
\hline \hline \multicolumn{1}{c}{ RMSD } & Papa & KEO \\
\hline$\alpha_{\text {CERES }}^{\text {month }}-\alpha_{\text {CERES }}^{\text {Clim,month }}$ & $0.013(19 \%)$ & $0.005(9 \%)$ \\
$-\mathrm{SW}_{\text {down,buoy }}\left(\alpha_{\text {CERES }}^{\text {month }}-\alpha_{\text {CERES }}^{\text {Clim,month }}\right)\left(\mathrm{W} \mathrm{m}^{-2}\right)$ & 0.8 & 0.9 \\
$\alpha_{\text {CERES }}^{\text {Clim,month }}-\alpha_{\text {ISCCP }}^{\text {Clim,month }}$ & $0.01(15 \%)$ & $0.008(14 \%)$ \\
$-\mathrm{SW}_{\text {down,buoy }}\left(\alpha_{\text {CERES }}^{\text {Clim,month }}-\alpha_{\text {ISCCP }}^{\text {Clim,month }}\right)\left(\mathrm{W} \mathrm{m}^{-2}\right)$ & 1.6 & 1.6 \\
$\alpha_{\text {CERES }}^{\text {month }}-\alpha_{\text {COARE }}$ & $0.02(29 \%)$ & $0.007(12 \%)$ \\
$-\mathrm{SW}_{\text {down,buoy }}\left(\alpha_{\text {CERES }}^{\text {month }}-\alpha_{\text {COARE }}\right)\left(\mathrm{W} \mathrm{m}^{-2}\right)$ & 0.9 & $0.01(18 \%)$ \\
\hline
\end{tabular}



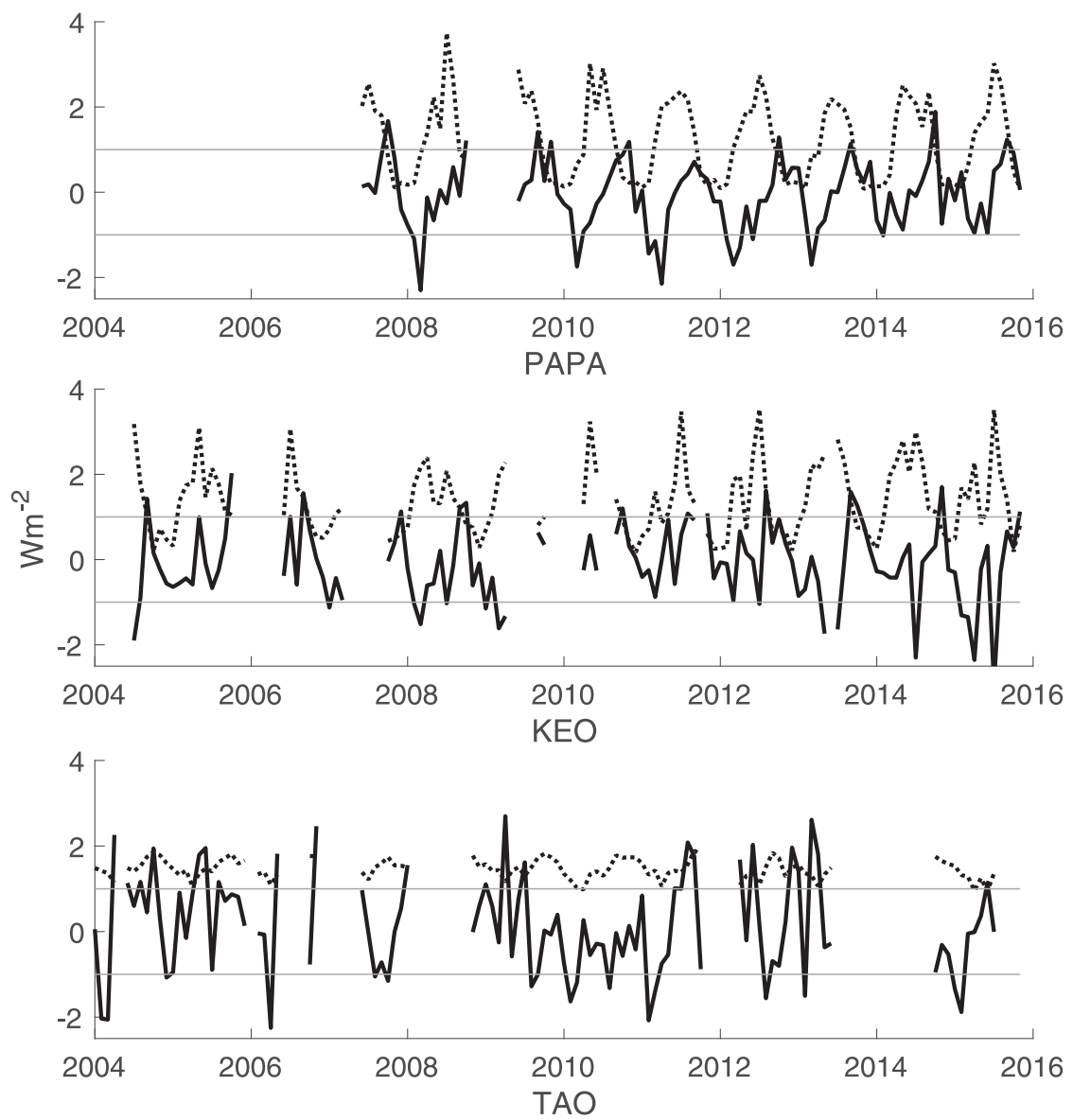

$-\mathrm{SW}_{\text {down,buoy }}^{\text {month }}\left(\alpha_{\text {CERES }}{ }^{-} \alpha_{\text {CERES }}^{\text {Clim,month }}\right) \ldots . . . . . S_{\text {down,buoy }}^{\text {month }}\left(\alpha_{\text {CERES }}^{\text {Clim,month }}-\alpha{ }_{\text {ISCCP }}^{\text {Clim,month }}\right)$

FIG. 5. Source uncertainties compared to interannual variability. Monthly $\mathrm{SW}_{\text {down,buoy }}$ $\left(\alpha_{\text {CERES }}^{\text {month }}-\alpha_{\text {CERES }}^{\text {Clim,month }}\right)$ (solid) and $\mathrm{SW}_{\text {down,buoy }}\left(\alpha_{\text {CERES }}^{\text {Clim,month }}-\alpha_{\text {ISCCP }}^{\text {Clim,month }}\right)$ (dotted) at each buoy location. Flat lines indicate the $1 \mathrm{~W} \mathrm{~m}^{-2}$ global average GCOS target, to which we refer for a target $\mathrm{SW}_{\text {net }}$ uncertainty. Climatologies are calculated from overlap period.

uncertainty alone. One could ask how much of the uncertainty in $\mathrm{SW}_{\text {net }}$ we show would be corrected by a calculation of $\mathrm{SW}_{\text {net }}$ that uses data from a single source (i.e., $\mathrm{SW}_{\text {down,ISCCP }}-\mathrm{SW}_{\text {up,ISCCP }}$ or $\mathrm{SW}_{\text {down,CERES }}-$ $\mathrm{SW}_{\text {up,CERES}}$ ). If $\mathrm{SW}_{\text {down,ISCCP }}$ is biased low compared to $\mathrm{SW}_{\text {down,CERES}}$, one might expect the difference of CERES and ISCCP $S W_{\text {net }}$ would be smaller when respective downwelling SW are used. Figure 6 shows the spatial pattern of the difference in $\mathrm{SW}_{\text {net }}$ from selfconsistent calculations, specifically $\mathrm{SW}_{\text {net,CERES }}-$

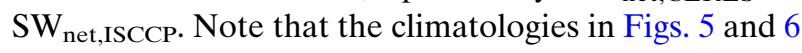
are from the ISCCP-CERES overlap period to ensure the best comparison of albedos. The longitudinal lines in Fig. 6 follow discontinuities between geostationary satellite observing areas. Discontinuities could be caused by retrieved cloud properties derived from different geostationary satellites that have different sets of channels. High RMSD (Fig. 6a) and mean differences (Fig. 6b) on coastlines are apparent, probably due to offsets in the grids used by each satellite and interference of land. CERES estimates higher $\mathrm{SW}_{\text {net }}$ in the midlatitudes, especially in stratocumulus regions, while ISCCP estimates slightly higher $\mathrm{SW}_{\text {net }}$ in parts of the tropics and subtropics. Because we do not have an independent reference for global albedo, in this paper we cannot attribute differences to errors in one or the other data sources. Instead, we interpret these differences as an uncertainty in global mean surface net shortwave radiation greater than the GCOS target of $1 \mathrm{~W} \mathrm{~m}^{-2}$.

\section{2) IMPLICATIONS FOR SST ESTIMATES}

Because air-sea fluxes are sensitive to sea surface temperature (SST), the biases in $T_{\mathrm{ML}}$ due to source product (Table 2), while relatively small, can have nonnegligible 
TABLE 2. Average $\Delta \mathrm{SW}_{\text {net }}=-\mathrm{SW}_{\text {down,buoy }}^{\text {month }}\left(\alpha_{\text {CERES }}^{\text {month }}-\alpha_{\text {CERES }}^{\text {Climonth }}\right)$ from (3) and cumulative $\Delta T_{\mathrm{ML}}$ from (5), each over a summer and winter season, due to (a) interannual variability and (b) difference between monthly CERES and ISCCP climatology. CERES monthly climatology is over full CERES period, 2001-16. The MLD is $65 \mathrm{~m}$ at Papa, $119 \mathrm{~m}$ at KEO, and $28 \mathrm{~m}$ at TAO in the winter half-year, and $43 \mathrm{~m}$ at Papa, $33 \mathrm{~m}$ at KEO, and $23 \mathrm{~m}$ at TAO in the summer half-year. The period 2010-11 was selected because it has no missing data from any buoy or satellite.

\begin{tabular}{|c|c|c|}
\hline & $-\mathrm{SW}_{\text {down,buoy }}\left(\alpha_{\text {CERES }}^{\text {month }}-\alpha_{\text {CERES }}^{\text {Clim,month }}\right)\left(\mathrm{W} \mathrm{m}^{-2}\right)$ & $-\mathrm{SW}_{\text {down,buoy }}\left(\alpha_{\text {CERES }}^{\text {month }}-\alpha_{\text {CERES }}^{\text {Clim,month }}\right)\left(\mathrm{W} \mathrm{m}^{-2}\right)$ \\
\hline (a) & March-August 2011 & September 2010-February 2011 \\
\hline Papa & -0.17 & -0.13 \\
\hline KEO & 0.37 & 0.07 \\
\hline \multirow[t]{3}{*}{ TAO } & 0.21 & -0.18 \\
\hline & $\Delta T_{\mathrm{ML}}$ due to $\alpha_{\mathrm{CERES}}^{\text {month }}-\alpha_{\mathrm{CERES}}^{\text {Clim,month }}\left({ }^{\circ} \mathrm{C}\right)$ & $\Delta T_{\mathrm{ML}}$ due to $\alpha_{\mathrm{CERES}}^{\text {month }}-\alpha_{\mathrm{CERES}}^{\text {Clim,month }}\left({ }^{\circ} \mathrm{C}\right)$ \\
\hline & March-August 2011 summer MLD & September 2010-February 2011 winter MLD \\
\hline Papa & -0.002 & -0.009 \\
\hline KEO & 0.048 & 0.002 \\
\hline \multirow[t]{2}{*}{ TAO } & 0.039 & -0.029 \\
\hline & $-\mathrm{SW}_{\text {down,buoy }}\left(\alpha_{\text {CERES }}^{\text {Clim,month }}-\alpha_{\text {ISCCP }}^{\text {Clim,month }}\right)\left(\mathrm{W} \mathrm{m}^{-2}\right)$ & $-\mathrm{SW}_{\text {down,buoy }}\left(\alpha_{\text {CERES }}^{\text {Clim,month }}-\alpha_{\text {CERES }}^{\text {Clim,month }}\right)\left(\mathrm{W} \mathrm{m}^{-2}\right)$ \\
\hline (b) & March-August 2011 & September 2010-February 2011 \\
\hline Papa & 2.08 & 1.57 \\
\hline KEO & 2.42 & 0.38 \\
\hline \multirow[t]{3}{*}{$\mathrm{TAO}$} & 0.02 & 0.94 \\
\hline & $\Delta T_{\mathrm{ML}}$ due to $\alpha_{\mathrm{CERES}}^{\text {Clim,month }}-\alpha_{\text {ISCCP }}^{\text {Clim,month }}\left({ }^{\circ} \mathrm{C}\right)$ & $\Delta T_{\mathrm{ML}}$ due to $\alpha_{\mathrm{CERES}}^{\text {Clim,month }}-\alpha_{\mathrm{ISCCP}}^{\text {Clim,month }}\left({ }^{\circ} \mathrm{C}\right)$ \\
\hline & March-August 2011 summer MLD & $\overline{\text { September 2010-February } 2011 \text { winter MLD }}$ \\
\hline Papa & 0.158 & 0.104 \\
\hline KEO & 0.050 & 0.014 \\
\hline TAO & 0.176 & 0.145 \\
\hline
\end{tabular}

impact. For example, as shown in Table 1 of Kubota et al. (2008), a $0.1^{\circ} \mathrm{C} \mathrm{SST} \mathrm{error} \mathrm{can} \mathrm{give} \mathrm{rise} \mathrm{to} \mathrm{a} 3.9 \mathrm{~W} \mathrm{~m}^{-2}$ error in net surface heat flux due to the sea surface temperature influence on latent and sensible heat fluxes and net longwave radiation. The actual uncertainty estimates in SST may be less than the $T_{\mathrm{ML}}$ error values reported here due to cross-thermocline mixing. Mixing deepens the mixed layer, making the vertically averaged temperature less sensitive to a given heat flux since the energy is distributed over a larger volume of water. The ultimate error in SST is difficult to quantify since the resulting errors in the turbulent air-sea heat fluxes and net longwave radiation will also cause a bias in the SST.

\section{3) Diurnal heat BUdget}

As discussed in section 1, an albedo product's time scale depends upon the temporal resolution of the $\mathrm{SW}_{\text {down }}$ and $\mathrm{SW}_{\text {up }}$ used to compute it in (1). A potential for error in $\mathrm{SW}_{\text {net }}$ arises when an albedo product computed at one time scale is applied to another. For example, a monthly climatological albedo or constant albedo are commonly used with in situ high-resolution $\mathrm{SW}_{\text {down }}$ to estimate a high-resolution $\mathrm{SW}_{\text {net }}$. In Table 3, we quantify the daily average error in $\mathrm{SW}_{\text {net }}$ and cumulative error in $T_{2 \mathrm{~m}}$ from using $\alpha_{\text {CERES }}^{\text {Clim,month }}$ or $\alpha_{\text {COARE }}$ rather than $\alpha_{\text {CERES }}^{\text {Clim,hour }}$. Table 3 shows that $\mathrm{SW}_{\text {net }}^{\text {hour }}$ from using monthly albedo (left side of table) has less error than $\mathrm{SW}_{\text {net }}^{\text {hour }}$ from using constant albedo (right side of table) at Papa and KEO but more error at TAO. It may be surprising that the simpler approximation does better at TAO. Figure 3 shows that $\alpha_{\text {COARE }}$ is higher than $\alpha_{\text {CERES }}^{\text {Clim,month }}$, which is always at the minimum of the hourly albedo, so $\alpha_{\mathrm{COARE}}$ compares more favorably with $\alpha_{\text {CERES }}^{\text {Clim,hour }}$. The $\mathrm{SW}_{\text {net }}$ bias is within the target GCOS uncertainty bounds for diurnal surface heating at Papa and KEO with a monthly climatology, but not with $\alpha_{\text {COARE}}$. The $\mathrm{SW}_{\text {net }}$ bias is outside the target uncertainty at TAO for both monthly climatology and $\alpha_{\text {COARE }}$ (Table 3 ). The resulting bias in $T_{2 \mathrm{~m}}$ seems fairly small everywhere. However, considering the sensitivity factor from Kubota et al. (2008) of $3.9 \mathrm{~W} \mathrm{~m}^{-2}\left(0.1^{\circ} \mathrm{C}\right)^{-1}$, this error in surface temperature at TAO in August could result in a net surface heat flux error of $1.1 \mathrm{~W} \mathrm{~m}^{-2}$ from $\alpha_{\text {CERES }}^{\text {Clim,hour }}-\alpha_{\text {CERES }}^{\text {Clim,month }}$ or $0.47 \mathrm{~W} \mathrm{~m}^{-2}$ from $\alpha_{\text {CERES }}^{\text {Clim,hour }}-\alpha_{\text {COARE. The overall surface }}$ temperature error is difficult to determine as it also depends on wind speed, surface temperature, and atmospheric boundary layer stability. While the average errors are not large, there may be periods and regions when the resulting errors are significantly larger. Monthly climatological albedo seems to be a good estimate at Papa and KEO; however, errors in SST could 

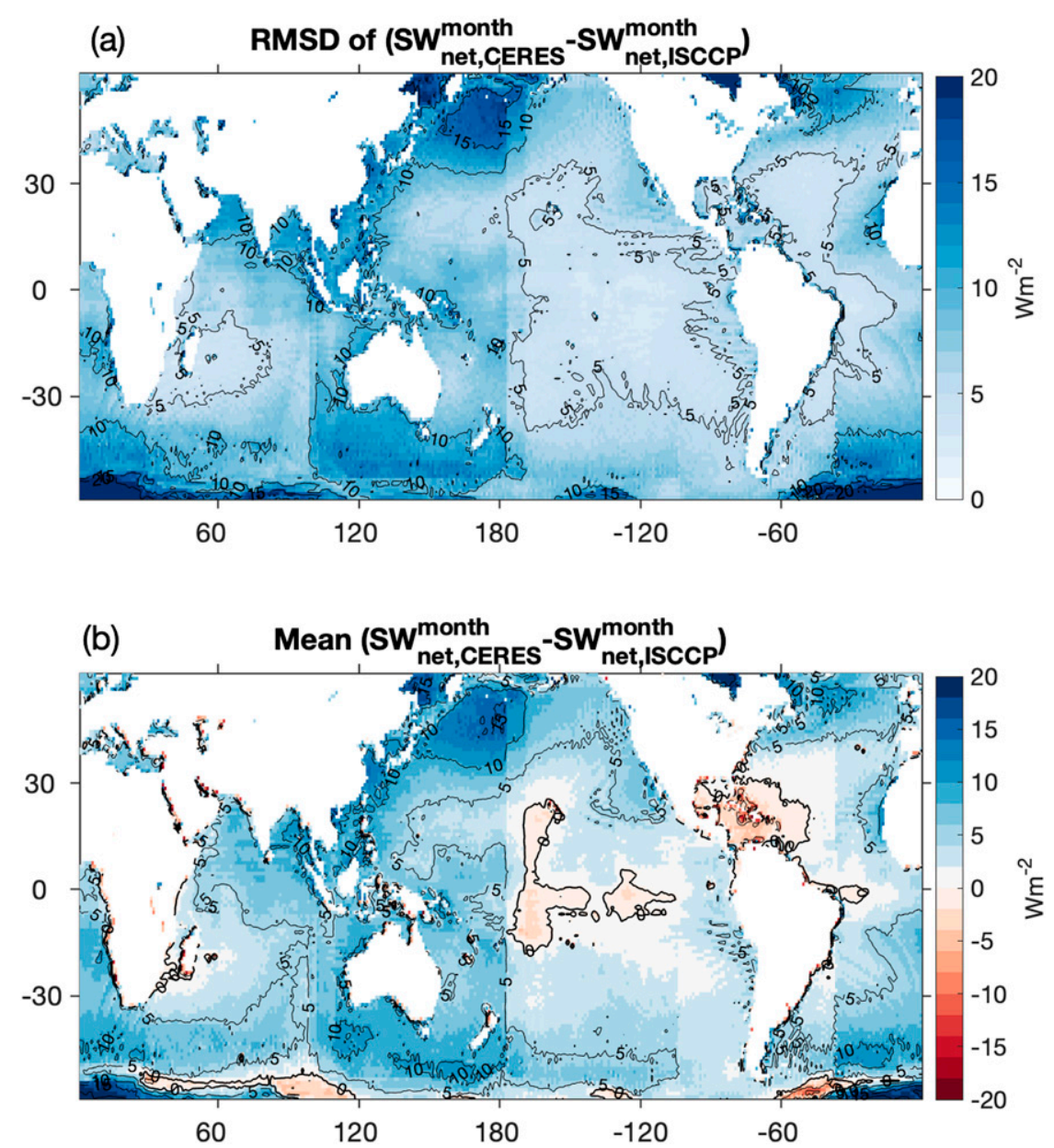

FIG. 6. (a) RMSD and (b) mean of $S_{\text {net,CERES }}^{\text {month }}-S_{\text {net,ISCCP }}^{\text {month }}$ from the overlap period, January 2001-December 2009. Contours are drawn every $5 \mathrm{~W} \mathrm{~m}^{-2}$ in (a) and (b), and the zero contour is darkened in (b).

accumulate over climatological time scales. Maintaining independent estimates of SST and continuing to whittle away at the surface flux uncertainty noted in this study will continue to be important.

\section{Conclusions}

The ISCCP estimates of albedo are consistently higher than those of CERES; the CERES-derived albedos would estimate that more energy is entering the ocean than ISCCP. The global-average RMSD from source differences is $6.6 \mathrm{~W} \mathrm{~m}^{-2}$, and is larger than that from ignoring interannual variability (not shown). The RMSD representing interannual variability ( $\left.\alpha_{\text {CERES }}^{\text {month }}-\alpha_{\text {CERES }}^{\text {Clim,month }}\right)$ at each buoy over the study period ranges from $7 \%$ to $19 \%$ of albedo, leading to an error in net shortwave radiation of $0.8-1.2 \mathrm{~W} \mathrm{~m}^{-2}$ at buoy locations (Table 1). The albedo diurnal cycle is on the order of the albedo seasonal cycle at Papa and KEO, and much greater at TAO, opening questions about the importance of the diurnal cycle to ocean surface heating estimates. We found that daily average surface heating bias from $\alpha_{\text {CERES }}^{\text {Clim,hour }}-\alpha_{\text {CERES }}^{\text {Clim,month }}$ is within $1 \mathrm{~W} \mathrm{~m}^{-2}$ at our buoy locations outside the tropics, but is larger than this at the site in the tropics (Table 3). The bias from $\alpha_{\text {CERES }}^{\text {Clim,hour }}-\alpha_{\text {COARE }}$ is outside target uncertainty at all stations, but has lower uncertainty at TAO than the bias from using the monthly climatological albedo. In short, TAO has larger-thantarget error unless one uses hourly albedo, but monthly climatologies are acceptable by this metric at Papa and KEO. Hourly $\mathrm{SW}_{\text {net }}$ with the albedo diurnal cycle is greater on average than with the constant albedo, suggesting that surface shortwave heating could be currently underestimated.

Differences in the satellite surface albedo estimates imply uncertainty beyond the guideline GCOS threshold in 
TABLE 3. Difference in surface heating estimated from hourly and monthly albedo $\left(\Delta \mathrm{SW} \mathrm{W}_{\text {net }}\right)$ and the resulting error in upper-2-m temperature $\Delta T_{2 \mathrm{~m}}$ in January and August. The left two columns show SW net and SST errors when neglecting the diurnal cycle in Eqs. (2) and (4) at each buoy location in climatological January and August. The right two columns show SW net and SST errors when using a constant albedo in Eqs. (2) and (4). $\Delta \mathrm{SW}_{\text {net }}$ is averaged over the climatological day, and $\Delta T_{2 \mathrm{~m}}$ is summed over the climatological day. The value of $\alpha_{\text {CERES }}^{\text {Clim,hour }}$ is calculated over the full CERES period (2001-16) for each separate month.

\begin{tabular}{|c|c|c|c|c|}
\hline & \multicolumn{2}{|c|}{$\begin{array}{c}-\mathrm{SW}_{\text {down,buoy }}^{\text {hour }}\left(\alpha_{\text {CERES }}^{\text {Clim,month }}-\alpha_{\text {CERES }}^{\text {Clim,hour }}\right)\left(\mathrm{W} \mathrm{m}^{-2}\right) \\
\text { Average }\end{array}$} & \multicolumn{2}{|c|}{$\begin{array}{c}-\mathrm{SW}_{\text {down,buoy }}^{\text {hour }}\left(\alpha_{\mathrm{COARE}}-\alpha_{\mathrm{CERES}}^{\text {Clim,hour }}\right)\left(\mathrm{W} \mathrm{m}^{-2}\right) \\
\text { Average }\end{array}$} \\
\hline & January & August & January & August \\
\hline Рapa & -0.35 & -0.02 & -3.7 & -0.24 \\
\hline KEO & -0.14 & 0.16 & -1.0 & 1.8 \\
\hline \multirow[t]{3}{*}{ TAO } & 1.91 & 3.86 & 1.0 & 1.5 \\
\hline & \multicolumn{2}{|c|}{$\begin{array}{c}\Delta T_{2 \mathrm{~m}} \text { due to } \alpha_{\text {CERES }}^{\text {Clim,month }}-\alpha_{\text {CERES }}^{\text {Clim,hour }}\left({ }^{\circ} \mathrm{C}\right) \\
\text { Cumulative, } 24 \mathrm{~h}\end{array}$} & \multicolumn{2}{|c|}{$\begin{array}{c}\Delta T_{2 \mathrm{~m}} \text { due to } \alpha_{\mathrm{COARE}}-\alpha_{\mathrm{CERES}}^{\text {Clim,hour }}\left({ }^{\circ} \mathrm{C}\right) \\
\text { Cumulative, } 24 \mathrm{~h}\end{array}$} \\
\hline & January & August & January & August \\
\hline Рapa & -0.002 & 0.0 & -0.02 & -0.002 \\
\hline KEO & -0.001 & 0.015 & -0.01 & 0.018 \\
\hline TAO & 0.015 & 0.03 & 0.01 & 0.012 \\
\hline
\end{tabular}

observational energy balance calculations. The source uncertainty is particularly worrisome as it may be a bias error rather than a random error (Fig. 6b). It would be useful to repeat these uncertainty analyses with in situ measurements in other ocean basins. Further efforts to close the energy budget at the atmosphere-ocean interface will be useful, as well as a comparison of these uncertainties with those in climate models for ocean-atmosphere heat exchange. Precise and accurate measurements of ocean surface albedo are important for useful monitoring and prediction of atmospheric heating, thermal expansion of the global ocean, and other impacts of warming on the ocean and atmosphere.

Acknowledgments. The authors are very grateful to the editor and three reviewers for their insightful comments and suggestions which have greatly improved the paper. The completion of this research was supported in part by the NOAA Ernest F. Hollings Scholarship. The moorings used here were supported by NOAA's Climate Program Office, Ocean Observing and Monitoring Division. The CERES data were obtained from the NASA Langley Research Center EOSDIS Distributed Active Archive Center. This is PMEL Contribution Number 4756. This publication is partially funded by the Joint Institute for the Study of the Atmosphere and Ocean (JISAO) under NOAA Cooperative Agreement NA15OAR4320063, Contribution Number 2018-187.

\section{REFERENCES}

Barkstrom, R. R., 1984: The Earth Radiation Budget Experiment (ERBE). Bull. Amer. Meteor. Soc., 65, 1170-1185, https://doi.org/ 10.1175/1520-0477(1984)065<1170:TERBE > 2.0.CO;2.
Booth, J. F., Y.-O. Kwon, S. Ko, R. J. Small, and R. Msadek, 2017: Spatial patterns and intensity of the surface storm tracks in CMIP5 models. J. Climate, 30, 4965-4981, https://doi.org/ 10.1175/JCLI-D-16-0228.1.

Colbo, K., and R. A. Weller, 2009: Accuracy of the IMET sensor package in the subtropics. J. Atmos. Oceanic Technol., 26, 1867-1890, https://doi.org/10.1175/2009JTECHO667.1.

Cox, C., and W. Munk, 1955: Some problems in optical oceanography. J. Mar. Res., 14, 63-78.

Cronin, M. F., C. W. Fairall, and M. J. McPhaden, 2006: An assessment of buoy-derived and numerical weather prediction surface heat fluxes in the tropical Pacific. J. Geophys. Res., 111, C06038, https://doi.org/10.1029/2005JC003324.

—_ , and Coauthors, 2013: Formation and erosion of the seasonal thermocline in the Kuroshio Extension Recirculation Gyre. Deep Sea Res. II, 85, 62-74, https://doi.org/10.1016/ j.dsr2.2012.07.018.

— N. A. Pelland, S. R. Emerson, and W. R. Crawford, 2015: Estimating diffusivity from the mixed layer heat and salt balances in the North Pacific. J. Geophys. Res. Oceans, 120, 73467362, https://doi.org/10.1002/2015JC011010.

de Boyer Montégut, C., G. Madec, A. S. Fischer, A. Lazar, and D. Iudicone, 2004: Mixed layer depth over the global ocean: An examination of profile data and a profile-based climatology. J. Geophys. Res., 109, C12003, https://doi.org/10.1029/ 2004JC002378.

Fairall, C. W., E. F. Bradley, D. P. Rogers, J. B. Edson, and G. S. Young, 1996: Bulk parameterization of air-sea fluxes for Tropical Ocean Global Atmosphere Coupled OceanAtmosphere Response Experiment. J. Geophys. Res., 101, 3747-3764, https://doi.org/10.1029/95JC03205.

$\longrightarrow,-$ J. E. Hare, A. A. Grachev, and J. B. Edson, 2003: Bulk parameterization of air-sea fluxes: Updates and verification for the COARE algorithm. J. Climate, 16, 571-591, https://doi.org/ 10.1175/1520-0442(2003)016<0571:BPOASF $>2.0 . C O ; 2$.

Feng, Y., Q. Liu, Y. Qu, and S. Liang, 2016: Estimation of the ocean water albedo from remote sensing and meteorological reanalysis data. IEEE Trans. Geosci. Remote Sens., 54, 850-868, https://doi.org/10.1109/TGRS.2015.2468054. 
GCOS, 2018: Atmosphere Surface Essential Climate Variables-Surface Radiation Budget according to NOAA National Center for Environmental Information. Global Climate Observing System, accessed 13 June 2018, https://www.ncdc.noaa.gov/gosic/ gcos-essential-climate-variable-ecv-data-access-matrix/gcosatmosphere-surface-ecv-surface-radiation-budget.

Hatzianastassiou, N., C. Matsoukas, A. Fotiadi, K. G. Pavlakis, E. Drakakis, D. Hatzidimitriou, and I. Vardavas, 2005: Global distribution of Earth's surface shortwave radiation budget. Atmos. Chem. Phys., 5, 2847-2867, https://doi.org/10.5194/ acp-5-2847-2005.

Jin, Z., T. P. Charlock, W. L. Smith, and K. Rutledge, 2004: A parameterization of ocean surface albedo. Geophys. Res. Lett., 31, L22301, https://doi.org/10.1029/2004GL021180.

Kato, S., and Coauthors, 2018: Surface irradiances of edition 4.0 Clouds and the Earth's Radiant Energy System (CERES) Energy Balanced and Filled (EBAF) data product. J. Climate, 31, 4501-4527, https://doi.org/10.1175/JCLI-D-17-0523.1.

Kiehl, J. T., and K. E. Trenberth, 1997: Earth's annual global mean energy budget. Bull. Amer. Meteor. Soc., 78, 197-208, https:// doi.org/10.1175/1520-0477(1997)078<0197:EAGMEB >2.0.CO;2.

Kubota, M., N. Iwabe, M. F. Cronin, and H. Tomita, 2008: Surface heat fluxes from the NCEP/NCAR and NCEP/DOE reanalyses at the Kuroshio Extension Observatory buoy site. J. Geophys. Res., 113 C02009, https://doi.org/10.1029/2007JC004338.

L'Ecuyer, T. S., and Coauthors, 2015: The observed state of the energy budget in the early twenty-first century. J. Climate, $\mathbf{2 8}$ 8319-8346, https://doi.org/10.1175/JCLI-D-14-00556.1.

Loeb, N. G., K. J. Priestley, D. P. Kratz, E. B. Geier, R. N. Green, B. A. Weilicki, P. O. Hinton, and S. K. Nolan, 2001: Determination of unfiltered radiances from the clouds and the Earth's radiant energy system instrument. J. Appl. Meteor., 40, 822-835, https://doi.org/10.1175/1520-0450(2001)040<0822: DOURFT $>2.0 . \mathrm{CO} ; 2$.

MacWhorter, M. A., and R. A. Weller, 1991: Error in measurements of incoming shortwave radiation made from ships and buoys. J. Atmos. Oceanic Technol., 8, 108-117, https://doi.org/ 10.1175/1520-0426(1991)008<0108:EIMOIS >2.0.CO;2.

Minobe, S., K. Y. Akira, K Nobumasa, S.-P. Xie, and R. J. Small, 2008: Influence of the Gulf Stream on the troposphere. Nature, 452, 206-210, https://doi.org/10.1038/nature06690.

Payne, R. E., 1972: Albedo of the sea surface. J. Atmos. Sci., 29 959-970, https://doi.org/10.1175/1520-0469(1972)029<0959: AOTSS $>2.0 . \mathrm{CO} ; 2$.

Pierce, D. W., T. P. Barnett, K. M. AchutaRao, P. J. Gleckler, J. M. Gregory, and W. M. Washington, 2006: Anthropogenic warming of the oceans: Observations and model results. J. Climate, 19, 1873-1900, https://doi.org/10.1175/ JCLI3723.1.
Rutan, D. A., F. G. Rose, N. M. Smith, and T. P. Charlock, 2001: Validation data set for CERES surface and atmospheric radiation budget (SARB). GEWEX Newsletter, No. 11 (1), International GEWEX Project Office, Silver Spring, MD, 11-12. , S. Kato, D. R. Doelling, F. G. Rose, L. T. Nguyen, T. E. Caldwell, and N. G. Loeb, 2015: CERES synoptic product: Methodology and validation of surface radiant flux. J. Atmos. Oceanic Technol., 32, 1121-1143, https://doi.org/10.1175/JTECHD-14-00165.1.

Schulz, E. W., S. A. Josey, and R. Verein, 2012: First air-sea flux mooring measurements in the Southern Ocean. Geophys. Res. Lett., 39, L16606, https://doi.org/10.1029/2012GL052290.

Stephens, G. L., and Coauthors, 2012: An update on Earth's energy balance in light of the latest global observations. Nat. Geosci., 5, 691-696, https://doi.org/10.1038/ngeo1580.

Taylor, J. P., J. M. Edwards, M. D. Glew, P. Hignett, and A. Slingo, 1996: Studies with a flexible new radiation code. II: Comparisons with aircraft short-wave observations. Quart. J. Roy. Meteor. Soc., 122, 839-861, https://doi.org/10.1002/ qj. 49712253204.

Trenberth, K. E., and J. T. Fasullo, 2010: Tracking Earth's energy. Science, 328, 316-317, https://doi.org/10.1126/science.1187272.

,$- \ldots$, and J. Kiehl, 2009: Earth's global energy budget. Bull. Amer. Meteor. Soc., 90, 311-324, https://doi.org/10.1175/ 2008BAMS2634.1.

Wielicki, B. A., B. R. Barkstrom, E. F. Harrison, R. B. Lee III, G. L. Smith, and J. E. Cooper, 1996: Clouds and the Earth's Radiant Energy System (CERES): An Earth Observing System Experiment. Bull. Amer. Meteor. Soc., 77, 853-868, https://doi.org/ 10.1175/1520-0477(1996)077<0853:CATERE > 2.0.CO;2.

Wild, M., D. Folini, C. Schär, N. Loeb, E. Dutton, and G. KönigLanglo, 2013: The global energy balance from a surface perspective. Climate Dyn., 40, 3107-3134, https://doi.org/10.1007/ s00382-012-1569-8.

Yu, L., and R. A. Weller, 2007: Objectively analyzed air-sea heat fluxes for the global ice-free oceans (1981-2005). Bull. Amer. Meteor. Soc., 88, 527-540, https://doi.org/10.1175/ BAMS-88-4-527.

Zhang, D., M. F. Cronin, C. Wen, Y. Xue, A. Kumar, and D. McClurg, 2016: Assessing surface heat fluxes in atmospheric reanalyses with a decade of data from the NOAA Kuroshio Extension Observatory. J. Geophys. Res. Oceans, 121, 6874-6890, https://doi.org/10.1002/2016JC011905.

Zhang, Y., W. B. Rossow, A. A. Lacis, V. Oinas, and M. I. Mishchenko, 2004: Calculation of radiative fluxes from the surface to top of atmosphere based on ISCCP and other global data sets: Refinements of the radiative transfer model and the input data. J. Geophys. Res., 109, D19105, https://doi.org/ 10.1029/2003JD004457. 